\section{Multimedia Educational Resource for Learning and Online Teaching (MERLOT). Access: http://www.merlot.org/.}

The MERLOT project is a successful and growing international cooperative of quality multimedia learning materials for higher education. MERLOT's mission is "to improve the effective-

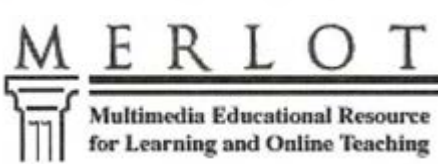

ness of teaching and learning by expanding the quantity and quality of peer-reviewed online leaming materials that can be easily incorporated into faculty-designed courses."

MERLOT's focus extends beyond a simple gateway or repository of multimedia learning materials. MERLOT links and organizes a high-quality collection of pedagogically sound resources delivered in the context of an "online community." In this context, MERLOT's members are not merely passive users, but are invited to be full participants as scholarly contributors, researchers, and peer evaluators. In addition, the project assures a high level of integrity through administrative support and sponsorship by distinguished higher education institutional partners, consortia, and professional organizations that have helped fund and support this ambitious initiative.

MERLOT leads users to over 8,500 Web-based digital leaming materials, which are available from Web sites around the world. This site serves as a sophisticated clearinghouse of selected materials as managed by MERLOT's discipline-based editorial boards.

Materials are organized into "discipline communities," such as biology, business, history, information technology, mathematics, music, teacher education, and world languages. In addition to URL and author/developer information, each resource may contain a peer review, user comments, starred ratings, links to related classroom/lab assignments, screen shots, and a descriptive abstract. Material types include simulations, animation, drill and practice, lecture presentations, tutorials, and other formats.

Searching across discipline communities is also effective as librarians who search for "information literacy" resources will discover over 60 rel- evant offerings gathered from a variety of discipline communities.

Anyone can search MERLOT and take advantage of its collected resources without registering for membership. Simple and advanced searching, subject browsing, and result ranking are provided. These tools are available to visitors and members alike and allow an effective range of desired search specificity. However, only members may contribute resources for peer review, post comments, and offer related assignments.

Members also may take advantage of the ability to create "personal collections," develop course "ePortfolios," and search an online directory of member profiles for professional networking opportunities.

A sip of this vintage MERLOT offers a robust, heady, yet full-bodied resource where educators and students are likely to uncover gems for immediate use in the classroom or, perhaps, rediscover favorite sites and materials enriched with commentary and linked to useful assignment ideas. —Mark A.Smith, New York State College of Ceramicsat Alfred University, msmitb@alfied.edu

Spine-health.com. Access: http://www. spine-health.com/.

The stated mission of Spine-health.com is to educate users about spine anatomy, disorders, and treatment in a comprehensive, impartial manner. The site is independently managed by a group of spine specialists and does not recommend or endorse any products.

The homepage is divided into five categories: "Find a Doctor," "Spine Topics," "Research," "Back Talk," and "Marketplace." "Find a Doctor" is a searchable directory of Web pages produced by board certified spine specialists. The specialists

\section{(pine-health.com your comprehensive resource for back pain}

Joni R. Roberts is associate university librarian for public services and collection development at Willamette University, e-mail: jroberts@willamette.edu, and Carol A. Drost is associate university librarian for technical services atWillamette University, e-mail: cdrost@willamette.edu 
listed pay a subscription fee to be included, so while the directory is useful, it is not comprehensive.

"Spine Topics" provides tutorials on the causes and treatment of back and neck pain, which are written specifically for the site and are peer reviewed by the Spine-health.com Medical Advisory Board. The advisory board is comprised of professionals in the fields of neurosurgery, orthopedic surgery, psychology, chiropractic, sports medicine, physiatry, radiology, neuroradiology, and physical therapy.

Spine-health.com claims that all content meets the quality criteria of the National Institutes of Health and the U.S. Department of Health and Human Services. Authors' credentials and contact information are provided. Useful black-andwhite and color line drawings, photographs, CT scans, and MRI images supplement the texts. "Research" offers articles exploring state-of-the-art treatment options. Items in this section undergo the same peer review process as the tutorials. "Back Talk" contains an annotated list of links, a sign up form to subscribe to the Spine-health.com newsletter, and an open back and neck pain message board.

"Marketplace" is a product ads section. From the homepage users can also view a series of sophisticated, interactive animation modules illustrating some of the most common spinal disorders and treatments.

Because alternate treatments are outlined (such as chiropractic vs. surgical), Spine-health.com is a useful, unbiased introductory reference for the treatment of common spinal disorders and is appropriate for students new to medicine. Although the text is geared to a novice audience, the graphics are useful to all levels of expertise in demonstrating spinal anatomy and treatment techniques not easily explainable with narrative. The animation modules alone make this site a valuable tool for those teaching in the health care professions. Spine-health.com also serves as an excellent example of a high caliber patient information site for students who will one day be educating patients.-Stusan M. Frey, DePuy Ortbopaedics, sfiey1@dpyus.jinj.com

U.S. Institute of Peace. Access: http:// www.usip.org/.

The U.S. Institute of Peace (USIP) is a federally funded think tank that was created in 1984 "to promote the prevention, management, and peaceful resolution of international conflicts."
With a budget of approximately $\$ 11$ million and a staff of 60 , the institute provides research grants, fellowships, professional training, education programs from high school through graduate school, conferences and workshops, library services, and publications. As a nonpartisan organization, USIP avoids advocacy on policy

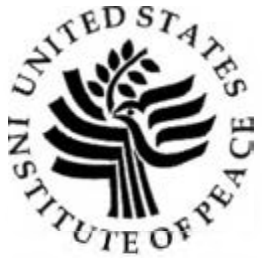
issues. In fact, when Congress founded the institute in 1984, it required that no more than eight members of the 15-member board be from the same political party. Board members are appointed by the President of the United States and confirmed by Congress. They are a mix of academics, leaders from nonprofits, and public figures.

According to a recent article in the Washington Post, USIP "has generally kept a low profile and developed a reputation as an institution that is solid, middle-of-the-road and even somewhat boring." Perfectly reflecting that, the USIP Web site has a plain design. In contrast to many other peace-related sites on the Internet, the USIP site contains no anti-war banners or flashing peace symbols, but rather substantive material on peace issues. It provides straightforward information on the programs offered by the institute, such as workshops, grant awards, funding for high school and college programs and curricula related to peace studies, and a national peace essay contest for high school students

As of this writing, the USIP site is highlighting information about the situation in Iraq. There is a "Special Report" on Iraq, plus extensive links to Web resources, and additional full-text reports and essays. USIP has been conducting a "Special Initiative on the Muslim World," and the Web site provides extensive reports and information on topics such as mediation, human rights, and Islamic perspectives on peace and violence.

The U.S. Institute of Peace has an extensive publishing program and any of their reports are freely available on the USIP Web site. Another useful feature of the site is the digital documents found under "Library and Links," which includes the "Peace Agreements Digital Collection" and the "Truth Commissions Digital Collection."

This site is recommended for students looking for information on peace initiatives around the world.-Susan E. Clank, University of Washington, seclank@u.wasbington.edu 
